phere passing over those lakes since the 20th of December, 1901, and the warm temperature has caused unusually great evaporation so that the water in those lakes is only about four feet higher at this date-February 9, 1902-than usual at this time of the year. There is also but slight increase of volcanic activity, indicated by an increased flow of gases and vapor from volcanic peaks. Only seven earthquakes in Western Nicaragua have occurred since November 15, each slight, from II. to IV. of the Rossi-Forel scale.

There are no indications of higher water in the Lakes this year. J. Crawfordes.

managua, Nicaragua,

February 9, 1902.

UNIO CONDONI IN THE JOHN DAY BEDS.

Professor J. C. Merriam informs me that he 'found great quantities of that species at the original locality.' As this form was not among the material sent to me for determination, I erroneously inferred that it had not been detected. The original locality, as stated by Dr. White, is the North Fork of John Day River, Oregon, at the angle of the big bend, longitude $119^{\circ} 40^{\prime}$, latitude $44^{\circ} 50^{\prime}$. $\mathrm{My}$ paper in Science January 24 last, pages 153-154, is hereby corrected in this particular. Robt. E. C. Stearns.

\section{NOTES ON INORGANIC CHEMISTRY.}

THE NEW SULFURIC ACID MANUFACTURE.

Attention has often been called within the last few years to the new process of making sulfuric acid from the pyrites-burner gases without the intervention of lead chambers, but the first authoritative description of the process, with the history of its development, was given in a lecture last fall by Dr. R. Knietsch before the German Chemical Society. This lecture has now been published in the Berichte of the Society and deserves notice, not only on account of the intrinsic importance of the subject, but also as being a conspicuous example of how the persistent investigations of trained chemists have succeeded in overcoming what seemed to be insuperable obstacles.

The catalytic action of platinum upon mixtures of gases was discovered by Sir Hum- phrey Davy in 1817, and in 1831 Peregrine Phillips, of Bristol, England, took out a patent for the manufacture of sulfuric acid by the action of finely divided platinum upon a mixture of sulfur dioxid and oxygen. This process, though exploited from time to time, and worked at by many chemists, came to nothing. In 1875 Clemens Winkler took up the study of this reaction, finding that the most favorable condition for this reaction is when the gases are present in the proportion of two volumes of sulfur dioxid to one of oxygen, and that the presence of other gases or even of an excess of either of those involved in the reaction is detrimental. Since, by decomposition, ordinary sulfuric acid yields a mixture of sulfur dioxid, oxygen and water, it was possible to utilize these gases in the manufacture of sulfur trioxid or of fuming sulfuric acid, by drying them to remove the water, and then leading them over platinum sponge. This was put into practical application with some success. This can, however, hardly be considered more than a very slight step toward the manufacture of ordinary oil of vitriol from the pyrites-burner gases.

The rapidly increasing development of the color-industry of Germany has occasioned a demand for enormous quantities of both concentrated and fuming sulfuric acid, and for the past decade the energies of the chemists of the great color corporations have been directed toward the problem of the manufacture of these acids without the intervention of the lead chambers and the platinum concentration stills. In these investigations Dr. Knietsch, of the Badische Anilin- und SodaFabrik, was a most important factor, and to him belongs a great share of the credit of having rendered the new process a commercial success.

The gases from the pyrites-burners consist of sulfur dioxid, nitrogen and an excess of oxygen from the air. When these gases were thoroughly purified and carried to the laboratory it was found that on passing over a 'contact mass' containing finely divided platinum, the sulfur dioxid was completely oxidized to the trioxid, or to sulfuric acid if water was present. When, however, an attempt was 